\title{
Soft computing techniques applied to finance
}

\author{
Asunción Mochón · David Quintana · Yago Sáez • \\ Pedro Isasi
}

Published online: 6 June 2007

\begin{abstract}
Soft computing is progressively gaining presence in the financial world. The number of real and potential applications is very large and, accordingly, so is the presence of applied research papers in the literature. The aim of this paper is both to present relevant application areas, and to serve as an introduction to the subject. This paper provides arguments that justify the growing interest in these techniques among the financial community and introduces domains of application such as stock and currency market prediction, trading, portfolio management, credit scoring or financial distress prediction areas.
\end{abstract}

Keywords Soft computing $\cdot$ Finance $\cdot$ Applications

\section{Introduction}

Soft computing is progressively gaining presence in the financial world. The number of potential applications is very large and, accordingly, so is the presence of applied research

\author{
A. Mochón (W) \\ Department of Applied Economics, UNED, $\mathrm{P}^{\circ}$ Senda del Rey, 11, \\ 28040 Madrid, Spain \\ e-mail: amochon@cee.uned.es \\ D. Quintana · Y. Sáez · P. Isasi \\ Department of Computer Science, University Carlos III de \\ Madrid, Madrid, Spain \\ D. Quintana \\ e-mail: david.quintana@uc3m.es \\ Y. Sáez \\ e-mail: yago.saez@uc3m.es \\ P. Isasi \\ e-mail: pedro.isasi@uc3m.es
}

in the literature. The aim of this paper is to present relevant application areas, as well as to serve as an introduction to the subject. For this reason, we not only bring in many examples, but we present arguments that justify why soft computing is a good response to many financial issues.

The paper is structured as follows: the first section deals with soft computing. There, we present a definition for the term and introduce the scope of the area of artificial intelligence. Then, we provide grounds to justify the rationale for using these techniques in finance. The section that follows presents several applications for soft computing in finance. For those interested in further information, we also provide some references for the literature. Finally, we present some conclusions.

\section{Soft computing}

The soft computing field covers a set of techniques that try to mimic the ability of the human mind to effectively employ modes of reasoning that are approximate rather than exact. The term was coined by Zadeh in the early nineties and its foundations can be traced back to earlier works such as a paper on fuzzy sets published in 1965 [1]; a 1973 paper on complex systems and decision processes [2]; or his 1981 paper on possibility theory and soft data analysis [3]. The concept was the subject of a specific paper published in 1994 [4]. The difference between traditional computing, also known as hard computing, and soft computing, is based on the importance given to issues like precision, certainty and rigor. These elements are at the core of hard computing. By contrast, and using the words of Zadeh, the point of departure in soft computing is the thesis that precision and certainty carry a cost and that computation, reasoning, and 
decision making should exploit, wherever possible, the tolerance for imprecision and uncertainty. That is, soft computing is expected to have an especially relevant role in domains where precise models are just too expensive, not practical or, simply, do not exist.

Once we have a broad definition of the field, the next issue to be covered is which specific techniques should be included in this area of artificial intelligence. Zadeh suggests that the main constituents of soft computing are fuzzy logic, neural network theory and probabilistic reasoning.

Fuzzy logic is derived from fuzzy set theory dealing with reasoning that is approximate rather than precisely deduced from classical predicate logic. It can be thought of as the application side of fuzzy set theory dealing with well though out real world expert values for a complex problem [5] Fuzzy logic is primarily concerned with imprecision. Unlike classical logic, it provides a way to arrive at conclusions based on premises that rely upon vague, ambiguous, imprecise, noisy, or incomplete information. What it deals with is approximate learning. The term should be understood in a broad sense that, apart from the basic framework, would also include rough sets and grey models.

Neural networks mainly deal with learning. This branch of computational science covers a wide range of function modeling techniques based on interconnected processing elements called neurons that work together to produce a specific output. Those artificial neurons are designed to mimic some properties of biological neural networks. Among the most important approaches we could mention are multilayer perceptrons, radial basis networks or self-organizing maps.

The basic interest of probabilistic reasoning is uncertainty. This wide umbrella groups together a range of techniques including belief networks, also known as Bayesian or causal networks; genetic algorithms, a global search heuristic inspired in biological evolution and parts of learning theory and chaotic systems.

Even though these three areas overlap to a certain extent, they should not be considered competing alternatives. In fact, these approaches are very complementary and often hybridize giving birth to new possibilities like evolutionary neural networks, fuzzy influence diagrams or neuro-fuzzy systems, among others.

All the above-mentioned techniques are general purpose and therefore, they are used in very different domains. Among the long list of fields that have profited from these techniques, there is one which we will focus our attention on: finance.

\section{Rationale for using soft computing in finance}

The amount of money that flows in the global financial market makes the reward of extracting exploitable regularities from financial data very attractive. There is also interest in the designing of new products or achieving a better understanding of financial dynamics. All this has resulted in efforts to gain an edge by any means.

The combination of increasing processing power and the exceptional amount of financial data available has extended the range of opportunities for exploring this field. Compared to the past, the need for simplifying assumptions is lower and the share of data-driven modeling is strengthened. Researchers currently have access to computational resources that allow them to obtain, process, and analyze high frequency financial data [6], price complex financial products [7] or analyze market behavior [8, 9]. Under these circumstances, soft computing offers a solid framework which is well suited for these tasks. Therefore, it is not surprising that the use of soft computing methods in finance is widespread, as evidenced by the number of publications and conferences that organize special sessions on the subject.

Soft computing deals with ill-structured problems very effectively and, in this context, it is a major advantage. Very often, the user has to overcome the issue of incomplete knowledge. There are situations in which it is far from evident whether the researcher is working with the right set of variables. A clear example of this would be short-term initial public offering underpricing prediction or bankruptcy prediction. Here, the researcher tackles a prediction or classification task with a set of variables that usually has the backing of a feasible financial rationale. Nevertheless, this set is not definitive, as the ultimate explanatory group of variables has yet to be identified.

Some other problems are evident when dealing with financial time series. Structural change is one of them. Frequently, the nature of the time series changes with time. On one hand, the influence of each of the precedent periods might vary. On the other hand, the predictability of the series might change with time, being more predictable in some periods than in others depending on the weight of the stochastic component of the underlying generation process; hence, the need for techniques that capture these changes and update the model dynamically.

Another issue to be taken into account is computational power. In some contexts, the need for a fast response, even if it is not very accurate, is more important than a late optimal response. The environment of stock trading would illustrate the point. Obtaining a gain that is lower than the maximum potential is better than obtaining the optimal strategy once the environment has changed and the opportunity is gone. Here, a good heuristic approach might be better than an exact method.

We could also cite complexity as a major problem. Sometimes we deal with large amounts of data represented by different variables that are interrelated in a way that we cannot model easily. We might have the relevant information, but 
if the dependencies are not evident, we need instruments to support the extraction of the rules that explain the behavior of the system.

As we have seen, the arguments supporting the advisability of using soft computing in finance are numerous. However this is not meant to be a comprehensive list of the features that justify the use of soft computing in this domain; for instance we have not mentioned the convenience of fuzzy representation for some applications, but point to the fact that both academics and practitioners face issues which soft computing resolves. What is more, the response is so convincing that it is being used very extensively in practice. The next section illustrates this statement presenting a range of specific financial problems in which soft computing has been successfully applied.

\section{Example application areas}

The application of soft computing in finance is especially recommended in those cases where we deal with problems whose nature is highly unstructured or which involve incomplete information or corrupted data, among others. These are frequent in the financial domain in areas like stock and currency market prediction, trading, portfolio management, credit scoring or financial distress prediction.

Securities market and foreign exchange prediction is one of the classic application areas. The aim here is to obtain accurate predictions for the behavior of a reference index. This index could be anything from composite market indexes or currency exchange rates to stock prices. In these time series prediction exercises, soft computing would generally take over the role of ARMA or GARCH econometric modeling. Usually the prime tool for this task are neural networks [1013], but soft computing methods can be combined in this context to obtain creative solutions. An example would be the one suggested by Srinivasa et al. [14], which relies on an evolutionary approach mixed with self organizing maps to cluster stock market data and fuzzy logic in order to fix learning rates.

Trading is very close to the previous application domain. Here we would consider the efforts to profit from the identification of market timing strategies. The aim of these would be exploiting regularities in price formation mechanisms in order to gain returns over a specific benchmark strategy, often buy-and-hold. Among the examples we could mention [15-17]. In this context there are many research papers where the authors build decision models based on indicators that are well known to practitioners of technical trading. Sometimes the structure of the rules is fixed a priori, and the system optimizes the parameters [18, 19]. Alternatively, the system would create new rules based on the mentioned indicators [20, 21]. Evolutionary computation, usually either genetic algorithms or genetic programming, very often are behind these efforts.

Portfolio management is another important subject in finance where soft computing can play a significant role. Here, most of the applications have the basic structure of constrained optimization problems. Often the target is either finding portfolio composition, a set of weights, that provides the maximum monetary gain subject to constraints like volatility and budget or, given a target return and other constraints, finding the portfolio structure that minimizes risk [22-24]. A different line of work is supporting passive portfolio selection. The problem could be stated as designing portfolios whose behavior is as close as possible to the one offered by a specific benchmark. The task can be daunting, especially when the set of acceptable alternative securities is large. Should this be the case, the assessment of all possible combinations is not an option and therefore, the problem demands a heuristic approach. Here, genetic algorithms and other evolutionary alternatives, sometimes combined with other techniques, provide promising competitive results [25-27].

Automated credit scoring methods is also an area where soft computing is well known. Here, the objective is creating systems that take the role of the human decision makers in charge of credit concession. They are generally classification systems that recommend either accepting or rejecting an application based on many different approaches [28] that differ in accuracy and capability to extract meaningful decision rules. Among these, we can cite neural networks [29-31] or mixed solutions [32, 33].

Business failure prediction has been an active research field in finance for a long time. Nevertheless, the number of parties that are affected by corporate failure is considerable. Investors, auditors, creditors or employees among many others, have a lot to gain from accurate forecasts for bankruptcy. One of the most important research lines approaches this as a classification task where the companies are classified in different categories depending on their financial soundness according to a set of relevant parameters. In this context, even though there is literature based on different techniques such as genetic algorithms [34] or rough sets [35]; artificial neural networks and neuro-fuzzy systems are especially widespread. We could mention examples like [36] or [37]. Atiya made a comprehensive survey in 2001 [38] gathering numerous examples of applications in this area.

There are several compilation works that would be useful for those looking for further information regarding potential applications of soft computing in finance. Among them, we could mention the books written by Almeida et al. [39], Chen [40], Chen and Wang [41] or Trippi and Turban [42] or surveys like the one authored by Vanstone and Tan [43] or Wong and Selvi [44]. 


\section{Conclusions}

The field of soft computing offers instruments that could provide good performance in domains where precise models are impractical, expensive or inexistent. In contrast to hard computing, soft computing methods deal effectively with the ill-structured problems that we find in the real world. Fuzzy logic, neural networks and probabilistic methods make a solid set that, either in their pure form or combined in hybrid solutions, can be used to tackle issues related to imprecision, learning and uncertainty.

Finance constitutes a good example of a domain where the problems are often characterized by the above mentioned features. Stock and currency market prediction, trading, portfolio management, credit scoring or financial distress prediction are paradigmatic examples of areas where researchers have to face incomplete information, corrupted data, or the need for fast response unlikely to be provided by an exact method.

It is no wonder that soft-computing is gaining momentum in the financial world. This perfect match between needs and instruments has resulted in an increasing body of academic literature devoted to these matters. Journals targeting the financial research community regularly publish research where soft computing is instrumental. The opposite is also true: more and more papers showing applications in finance are published in journals focused on artificial intelligence. A similar trend can be observed in the academic conference circuit.

We do not expect the mentioned trend to reverse soon. The curricula of a growing number of graduate school programs in finance include subjects where neural networks or genetic algorithms are taught alongside econometrics or traditional optimization methods. We would expect this to have a strong influence in the mid-term as the number of both financial researchers and practitioners that are aware of the existence of soft-computing is to likely grow substantially. We consider this to be an exciting opportunity for those interested in working at the intersections of these two fields. The future looks promising.

Acknowledgements This article has been financed by the Spanish founded research MCyT project OPLINK, Ref: TIN2005-08818-C0402 and CAM-UC3M project Computación con Inspiración Biológica para la Minería de Datos, Ref: UC3M-DEC-05-029.

\section{References}

1. Zadeh LA (1965) Fuzzy sets. Inf Control 8(3):338-353

2. Zadeh LA (1973) Outline of a new approach to the analysis of complex systems and decision processes. IEEE Trans Syst Man Cybern 3:28-44

3. Zadeh LA (1981) Possibility theory and soft data analysis. In: Cobb L, Thrall RM (eds) Mathematical frontiers of the social and policy sciences. Westview, Boulder, pp 69-129
4. Zadeh LA (1994) Fuzzy logic, neural networks, and soft computing. Commun ACM 37(3):77-84

5. Klir GJ, Yuan B, Clair USt (1997) Fuzzy set theory: foundations and applications. Prentice Hall, New York

6. Bolland PJ, Connor JT (1997) A constrained neural network Kalman filter for price estimation in high frequency financial data. Int J Neural Syst 8(4):399-415

7. Malliaris M, Salchenberger L (1993) A neural network model for estimating option prices. J Appl Intell 3(3):193-206

8. Palmer RG, Arthur WB, Holland JH, LeBaron B, Tayler P (1994) Artificial economic life: a simple model of a stockmarket. Phys D 75:264-274

9. Lettau M (1997) Explaining the facts with adaptive agents: the case of mutual funds flows. J Econ Dyn Control 21:1117-1148

10. Sapena O, Botti V, Argente E (2003) Application of neural networks to stock prediction in "pool" companies. Appl Artif Intell 17(7):661-673

11. Yao J, Poh HL (1995) Forecasting the KLSE index using neural networks. In: Proceedings of the IEEE international conference on neural networks, London, pp 1012-1017

12. Baestaens DE, van den Bergh WM (1995) Tracking the Amsterdam stock index using neural networks. In: Neural networks in the capital markets. Wiley, New York, pp 149-162

13. Wei H, Lai KK, Nakamori Y, Wang SY (2004) Forecasting foreign exchange rates with artificial neural networks: a review. Int J Inf Technol Decis Mak 3:145-165

14. Srinivasa KG, Sridharan K, Deepa Shenoy P, Venugopal KR, Patnaik LM (2004) EASOM: an efficient soft computing method for predicting the share values. In: Proceedings of IASTED international conference on artificial intelligence and applications, Austria, Innsburg, pp 264-269

15. Austin M, Looney C, Zhuo J (1997) Security market timing using neural network models. New Rev Appl Expert Syst 3:3-14

16. Doeksen B, Abraham A, Thomas J, Paprzycki M (2005) Real stock trading using soft computing models. In: Proceedings of the information technology: coding and computing, ITCC 2005, vol 2, pp 162-167

17. Tan PY (1994) Using genetic algorithm to optimize an oscillatorbased market timing system. In: Proceedings of the second Singapore international conference on intelligent systems SPICIS'94, Singapore, pp 115-122

18. Fernández-Rodríguez F, González-Martel C, Sosvilla-Rivero S (2005) Optimization of technical rules by genetic algorithms: evidence from the Madrid stock market. Appl Financ Econ 15(11):773-775

19. Chan KCC, Foo KT (1995) Enhancing technical analysis in the Forex market using neural networks. In: Proceedings of the IEEE international conference on neural networks, Australia, pp 1023 1027

20. Allen F, Karjalainen R (1999) Using genetic algorithms to find technical trading rules. J Financ Econ 51:245-271

21. Neely CJ, Weler P, Dittmar R (1997) Is technical analysis in the foreign exchange market profitable? A genetic programming approach. J Financ Quant Anal 32(4):405-426

22. Casas A ( 2005) Reducing portfolio volatility with artificial neural networks. In: Proceedings of the IASTED international conference on artificial intelligence, Lynbrook, Austria, pp 152-157

23. Lai KK, Yu L, Wang S, Zhou C (2006) A double-stage genetic optimization algorithm for portfolio selection. In: Proceedings of the 13th international conference on neural information processing, Hong Kong, vol 3, pp 928-937

24. Liu YC, Wang T, Gao LQ, Ren P, Li BZ (2005) Fuzzy portfolio optimization model based on worst-case VaR. In: Proceedings of 2005 international conference on machine learning and cybernetics, vol 6, pp 3512-3516 
25. Jeurissen $R$, van den Berg $\mathbf{J}$ (2005) Index tracking using a hybrid genetic algorithm. In: Proceedings of the CIMA'05 conference, Istanbul. Paper number 910

26. Beasley JE, Meade N, Chang TJ (2003) An evolutionary heuristic for the index tracking problem. Eur J Oper Res 148:621-643

27. Shapcott J (1992) Index tracking: genetic algorithms for investment portfolio selection. Report EPCC-SS92-24, Edinburgh Parallel Computing Centre, The University of Edinburgh

28. Thomas LC (2000) A survey of credit and behavioural scoring: forecasting financial risk of lending to customers. Int J Forecast $16: 149-172$

29. Sarlija N, Bensic M, Zekic-Susac M (2006) A neural network classification of credit applicants in consumer credit scoring. In: Proceedings of the 24th IASTED international conference on artificial intelligence and applications, Innsbruck, Austria, pp 205-210

30. Malhotra R, Malhotra DKR (2003) Evaluating consumer loans using neural networks. Omega 31:83-96

31. Lai KK, Wang YuLS, Zhou L (2006) Neural network metalearning for credit scoring. In: Lecture notes in computer science, vol 4113 , pp 403-408

32. Yobas MB, Crook JN, Ross P (2000) Credit scoring using neural and evolutionary techniques. IMA J Manag Math 11(2):111-125

33. Hoffmann F, Baesens B, Mues C, Vanthienen J (2006) Inferring descriptive and approximate fuzzy rules for credit scoring using evolutionary algorithms. Eur J Oper Res 177(1):540-555

34. Shin KA (2002) Genetic algorithm application in bankruptcy prediction modeling. Int J Expert Syst Appl 23:321-328

35. Mckee TE (2000) Developing a bankruptcy prediction model via rough sets theory. Int J Intell Syst Account Financ Manag 9(3):159-173
36. Odom M, Sharda RA (1990) Neural network model for bankruptcy prediction. In: Proceedings of the IEEE international conference on neural networks, vol II, pp 163-168

37. Coats PK, Fant LF (1993) Recognizing financial distress patterns using a neural network tool. Financ Manag 22(3):142-155

38. Atiya AF (2001) Bankruptcy prediction for credit risk using neural networks: a survey and new results. IEEE Trans Neural Netw 12(4):929-935

39. Almeida Ribeiro R, Zimmermann HJ, Yager R, Kacprzyk J (1999) Soft computing in financial engineering. In: Studies in fuzziness and soft computing. Springer, Heidelberg

40. Chen S (ed) (2002) Evolutionary computation in economics and finance, studies in fuzziness and soft computing. Springer, New York

41. Chen S, Wang P (eds) (2003) Computational intelligence in economics and finance, advanced information processing. Springer, New York

42. Trippi RR, Turban E (eds) (1996) Neural networks in finance and investing: Using artificial intelligence to improve real world performance, revised edn. IRWIN Professional, Chicago

43. Vanstone B, Tan C (2003) A survey of the application of soft computing to investment and financial trading. In: Proceedings of the Australian and New Zealand intelligent information systems conference, Sydney, pp 211-216

44. Wong BK, Selvi Y (1998) Neural network applications in finance: a review and analysis of literature (1990-1996). Inf Manag 34:129-139 